\title{
Interobserver variability impairs radiologic grading of primary graft dysfunction after lung transplantation
}

\author{
Stefan Schwarz, MD, ${ }^{\mathrm{a}}$ Moritz Muckenhuber, MD, ${ }^{\mathrm{a}}$ Alberto Benazzo, MD, ${ }^{\mathrm{a}}$ Lucian Beer, MD, \\ Florian Gittler, MD, ${ }^{b}$ Helmut Prosch, MD, ${ }^{b}$ Sebastian Röhrich, MD, ${ }^{b}$ Ruxandra Milos, MD, \\ Thomas Schweiger, MD, PhD, ${ }^{\mathrm{a}}$ Peter Jaksch, MD, ${ }^{\mathrm{a}}$ Walter Klepetko, MD, ${ }^{\mathrm{a}}$ and \\ Konrad Hoetzenecker, $\mathrm{MD}, \mathrm{PhD}^{\mathrm{a}}$
}

\section{ABSTRACT}

Objectives: The current score for primary graft dysfunction after lung transplantation relies heavily on chest radiographs, and radiologic judgment can make the difference between the lowest (primary graft dysfunction 0) and the highest (primary graft dysfunction 3) grade. This study aimed to evaluate interobserver variability of the scoring of postoperative chest radiographs and its impact on primary graft dysfunction grades in a large single-center cohort.

Methods: We retrospectively analyzed 497 lung transplantations performed between January 2010 and July 2016 at the Medical University of Vienna. Five trained thoracic radiologists were asked to independently examine postoperative chest radiographs performed at 0 to 6 hours, 24 hours, 48 hours, and 72 hours after arrival at the intensive care unit. Interobserver variability was calculated using Fleiss' kappa $(\kappa)$ statistics.

Results: A total of 1988 chest radiographs were evaluated. Consensus among all 5 radiologists was found in only 826 cases $(43.0 \%)$. At 0 to 6 hours and 24 hours, only a moderate agreement was found among the 5 radiologists $(\kappa=0.456$ and 0.456 , respectively), and agreement was even worse at 48 and 72 hours ( $\kappa=0.405$ and $\kappa=0.409$ ). On the basis of this high interobserver variability, best and worst case scenarios were calculated leading to primary graft dysfunction 3 rates of $8.4 \%$ versus $28.4 \%$ at 0 to 6 hours, $1.8 \%$ versus $4.8 \%$ at 24 hours, $2.0 \%$ versus $5.3 \%$ at 48 hours, and $0.2 \%$ versus $3.1 \%$ at 72 hours. A high recipient body mass index and size-reduced transplants were found to be factors associated with higher rates of interobserver variability.

Conclusions: The substantial interobserver variability found in this retrospective analysis underlines the difficulty to adequately grade post-transplant organ function. Future revisions of the primary graft dysfunction grading should take this problem into consideration. (J Thorac Cardiovasc Surg 2019;158:955-62)

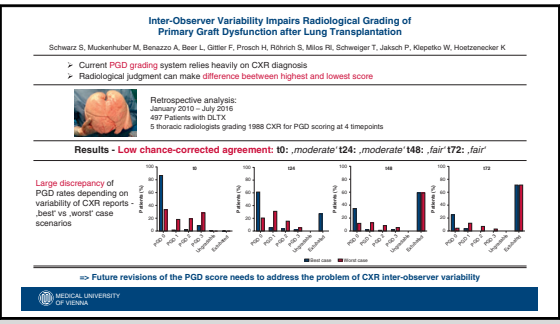

High interobserver variability of chest radiograph diagnosis after LTX significantly impairs grading of PGD.

\section{Central Message}

Current PGD grading relies heavily on the binary radiologic component. Interobserver variability in grading chest radiographs after LTx is substantial and therefore impairs the assessment of PGD scores. Future revisions of the PGD score should take this issue into consideration.

\section{Perspective}

The clinical significance of the ISHLT PGD score remains controversial because the grading is impaired by a high degree of interobserver variability in interpreting chest radiographs. An improved scoring system should place more weight on functional measurements and redefine the central role of the radiologic component.

See Commentaries on pages 963 and 965.
From the aivision of Thoracic Surgery, Medical University of Vienna, Vienna, Austria; and 'bepartment of Biomedical Imaging and Image-guided Therapy, Medical University of Vienna, Vienna, Austria.

Read at the 98th Annual Meeting of The American Association for Thoracic Surgery, San Diego, California, April 28-May 1, 2018.

Received for publication May 21, 2018; revisions received Feb 11, 2019; accepted for publication Feb 14, 2019; available ahead of print June 14, 2019.

Address for reprints: Konrad Hoetzenecker, MD, PhD, Division of Thoracic Surgery, Medical University of Vienna, Waehringer Guertel 18-20, A-1090 Vienna, Austria (E-mail: konrad.hoetzenecker@meduniwien.ac.at).

0022-5223/\$36.00

Copyright (c) 2019 by The American Association for Thoracic Surgery https://doi.org/10.1016/j.jtcvs.2019.02.134
Although outcomes after lung transplantation (LTx) have constantly improved over the last decades, primary graft dysfunction (PGD) still remains one of the main obstacles in the early perioperative period. ${ }^{1}$ PGD is currently graded

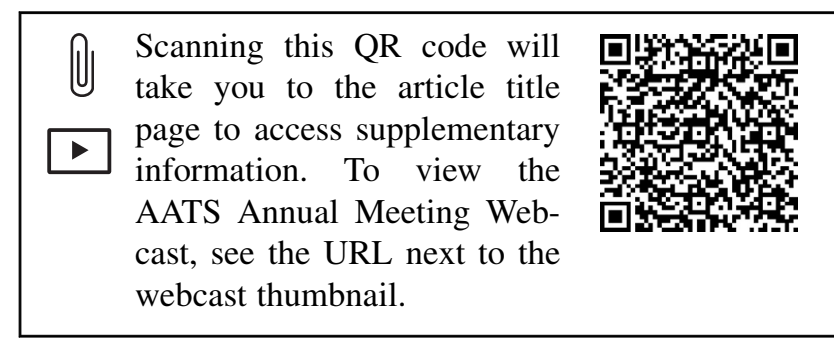




Abbreviations and Acronyms
$\begin{aligned} \text { ARDS } & =\text { acute respiratory distress syndrome } \\ \text { BMI } & =\text { body mass index } \\ \text { ECMO } & =\text { extracorporeal membrane oxygenation } \\ \text { ISHLT }= & \text { International Society for Heart and Lung } \\ & \text { Transplantation } \\ \text { LTx }= & \text { lung transplantation } \\ \text { P/F } \quad=\text { partial pressure of arterial oxygen/fraction } & \text { of inspired oxygen } \\ \text { PGD }= & \text { primary graft dysfunction } \\ \text { t0 } & =0 \text { to } 6 \text { hours } \\ \text { t24 } & =24 \text { hours } \\ \text { t48 } & =48 \text { hours } \\ \text { t72 } & =72 \text { hours }\end{aligned}$

using a scoring system that was proposed by the International Society for Heart and Lung Transplantation (ISHLT) in $2005^{2}$ and revised in 2016 . $^{3}$ According to these recommendations, PGD grades should be measured at different time points: 0 to 6 hours (t0), 24 hours (t24), 48 hours (t48), and 72 hours (t72) after transplantation. Grading is based on the ratio of arterial partial pressure of oxygen and fraction of inspired oxygen and the presence or absence of bilateral infiltrations consistent with reperfusion edema in chest radiographs. The judgment of chest radiographs has a major impact on PGD grading and can make the difference between the lowest (PGD 0) and highest (PGD 3) scores.

We aimed to determine the agreement rate of trained radiologists on postoperative chest radiographs and its impact on PGD grades studying a contemporary, large singlecenter cohort of LTx recipients.

\section{MATERIALS AND METHODS \\ Patient Cohort and Study Outline}

A total of 497 patients who received double LTx in our institution between January 2010 and July 2016 were included in this retrospective, single-center analysis. Single LTx and multiorgan transplantations were excluded from this study. Patient demographics, operative parameters, and outcome data were extracted from our institutional LTx database and the hospital patient data management system.

Five thoracic radiology specialists with several years of experience in assessing chest radiographs in LTx recipients participated in the study. The raters were asked to retrospectively judge postoperative chest radiographs of all included patients at 4 time points ( $\mathrm{t} 0, \mathrm{t} 24, \mathrm{t} 48$, and $\mathrm{t} 72$ hours) after transplantation, resulting in a total of $1988 \mathrm{x}$-rays. The experts were blinded to the clinical details, course, and outcome of the patients. Only the patient's name, date of birth, and time of transplantation were provided to the raters to facilitate viewing radiographs using the institution's standard image viewing software (IMPAX EE, Agfa Healthcare, Mortsel, Belgium). Raters were asked to independently assess the radiographs for presence or absence of bilateral infiltrations consistent with reperfusion edema and answer in binary form (yes/no).

\section{Subgroup Analysis}

To address potential bias introduced by the blinding of raters to preoperative and intraoperative details, the radiologists were asked to reevaluate the radiographs of a subgroup of patients a second time. For this purpose, a random subgroup of 100 patients was drawn from the original cohort and radiologists were provided with basic preoperative and intraoperative characteristics for each patient (underlying diagnosis, recipient age, urgency status, intubation before transplantation, extracorporeal life support bridging, recipient body mass index [BMI], last donor partial pressure of arterial oxygen, use of ex vivo lung perfusion, total surgery time, number of administered erythrocyte and fresh-frozen plasma concentrates, and total graft ischemic time).

\section{Statistical Analysis and Primary Graft Dysfunction Scoring}

Percentages of full agreement among the 5 raters were calculated for each of the 4 time points. Chance-corrected agreement was calculated using Fleiss' kappa method.

PGD scores were calculated for all time points according to ISHLT guidelines using partial pressure of arterial oxygen/fraction of inspired oxygen $(\mathrm{P} / \mathrm{F})$ ratios and chest radiograph interpretation (Table E1). For patients on postoperative extracorporeal membrane oxygenation (ECMO), the PGD score was ungradable in case of a clear x-ray or PGD 3 in case of bilateral infiltrations. Extubated patients were not assigned a PGD score, but their radiographs at all time points were included in the interobserver agreement analysis.

To highlight the maximal impact of interobserver variability on PGD scoring, PGD grades were assigned using both a best case and a worst case scenario of chest $\mathrm{x}$-ray diagnosis. In cases of full agreement among raters, their unanimous decision was used for calculating the score. For the remaining cases with a discordant $\mathrm{x}$-ray reporting, PGD grading was simulated assuming a most favorable $\mathrm{x}$-ray (no infiltrations) for the best case scenario or a nonfavorable $\mathrm{x}$-ray (infiltrations present) for the worst case scenario. Furthermore, a subgroup analysis on patients with a P/F ratio lower than 200 at the respective time points was performed.

In an additional set of analyses, chance-corrected agreement between subgroups was calculated on the basis of the patient's BMI and type of transplantation (whole lungs vs atypical size reduction vs lobar transplantation).

Data were analyzed using IBM SPSS Statistics (New York, NY) software version 24.0. For calculation of Fleiss' kappa, a free SPSS software extension was used. ${ }^{4}$ To interpret kappa values, guidelines proposed by Altman $^{5}$ and Landis and Koch ${ }^{6}$ were used (Table E2). Figures 1 and 2 were produced with GraphPad Prism 6 (GraphPad Software, San Diego, Calif).

\section{RESULTS \\ Descriptive Analysis}

The study cohort consisted of 497 LTx recipients. The main underlying diagnoses were COPD $(36.0 \%)$, pulmonary fibrosis $(24.7 \%)$, and cystic fibrosis $(24.5 \%)$. Twenty-eight patients $(5.6 \%)$ were bridged to LTx by short-term mechanical ventilation, and 18 patients $(3.6 \%)$ were bridged by extracorporeal life support. In 53 patients $(10.7 \%)$, ex vivo lung perfusion of the donor lung was performed. Overall mean ischemic time was $345 \pm 72$ minutes, and the mean duration of surgery was $281 \pm 56$ minutes. ECMO was used for intraoperative support in 393 patients $(79.1 \%)$, and 100 patients $(20.1 \%)$ underwent transplantation without support. Cardiopulmonary bypass was used in 4 patients $(0.8 \%)$. A total of 231 patients $(46.5 \%)$ received whole lungs, and $197(39.6 \%)$ transplants were sizereduced by extra-anatomic resection of the middle lobe or 


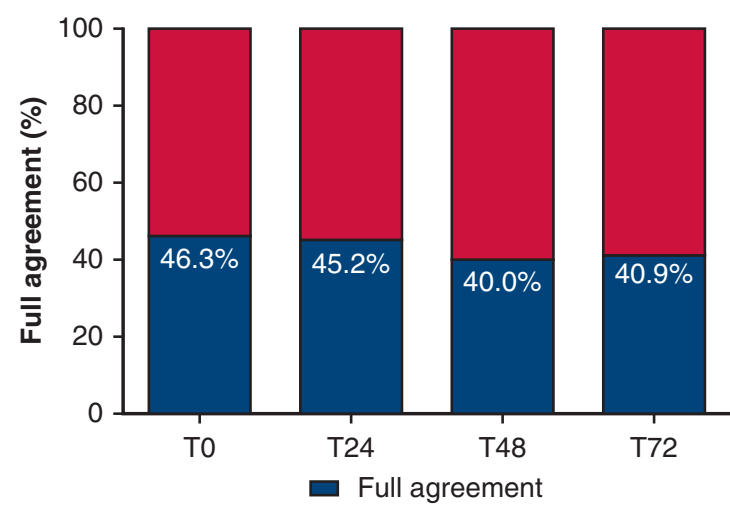

FIGURE 1. Percentages of full agreement on the diagnosis of chest radiographs among 5 experienced radiologists at different time points after LTx. $t 0,0$ to 6 hours; $t 24,24$ hours; $t 48,48$ hours; $t 72,72$ hours.

the lingula. Sixty-nine patients $(13.9 \%)$ received tri-lobar or bi-lobar transplantations. Detailed patient demographics are shown in Table 1.

\section{Interobserver Agreement}

A total of 1988 chest radiographs were independently examined by 5 radiologists. Full agreement of all 5 raters was found in 826 cases $(43.0 \%)$. In $266(32.2 \%)$ of these radiographs, the uniform diagnosis was "presence of infiltrations," whereas in 560 cases $(67.8 \%)$ no infiltrations were found. At t0, radiologists were in full agreement in 224 cases $(46.3 \%)$. They agreed on 216 radiographs $(45.2 \%)$ at $\mathrm{t} 24,191$ radiographs $(40.0 \%)$ at $\mathrm{t} 48$, and $195 \mathrm{ra}-$ diographs $(40.9 \%)$ at $\mathrm{t} 72$. Percentages of agreement at different time points are depicted in Figure 1.
Fleiss' kappa statistics were calculated to quantify chance-corrected agreement. For both t0 and t24, Fleiss' kappa was 0.456 , corresponding to a moderate agreement. At $\mathrm{t} 48$ and $\mathrm{t} 72$, agreement was worse with a kappa of 0.405 and 0.409 , respectively. An in-depth analysis revealed that these poor agreement rates were not due to a single outlier (data not shown). Because radiologists were completely blinded to all clinical parameters, and detailed background knowledge might have changed their judgment, we asked the raters to reevaluate a randomly created subgroup of 100 patients, this time having full information on preoperative and intraoperative patient data. Kappa values did not improve, and raters only reached "fair" chance-corrected agreement levels across all time points ( 0.335 at t0, 0.322 at t24, 0.365 at t 48 , and 0.358 at $\mathrm{t72}$ ) (Table 2). In a next set of analyses, we determined whether certain preoperative and intraoperative factors were associated with interrater variability. Atypical size reductions (middle lobe and lingula resections) and lobar transplantations led to markedly lower kappa values of agreement at t0 with 0.396 and 0.311 , respectively, compared with whole LTxs with 0.520. In addition, high patient BMI greater than 25 was associated with reduced interobserver agreement. This difference was most pronounced at 448 and t72 with a kappa of 0.224 and 0.248 compared with 0.445 and 0.455 for BMI 18 to 25 or 0.457 and 0.429 for BMI less than 18 (Table 3).

\section{Primary Graft Dysfunction Scores}

Across all time points, 231 cases $(11.6 \%)$ with a P/F ratio of less than $200 \mathrm{~mm} \mathrm{Hg}$ were identified $(\mathrm{n}=160$ at $\mathrm{t} 0$,

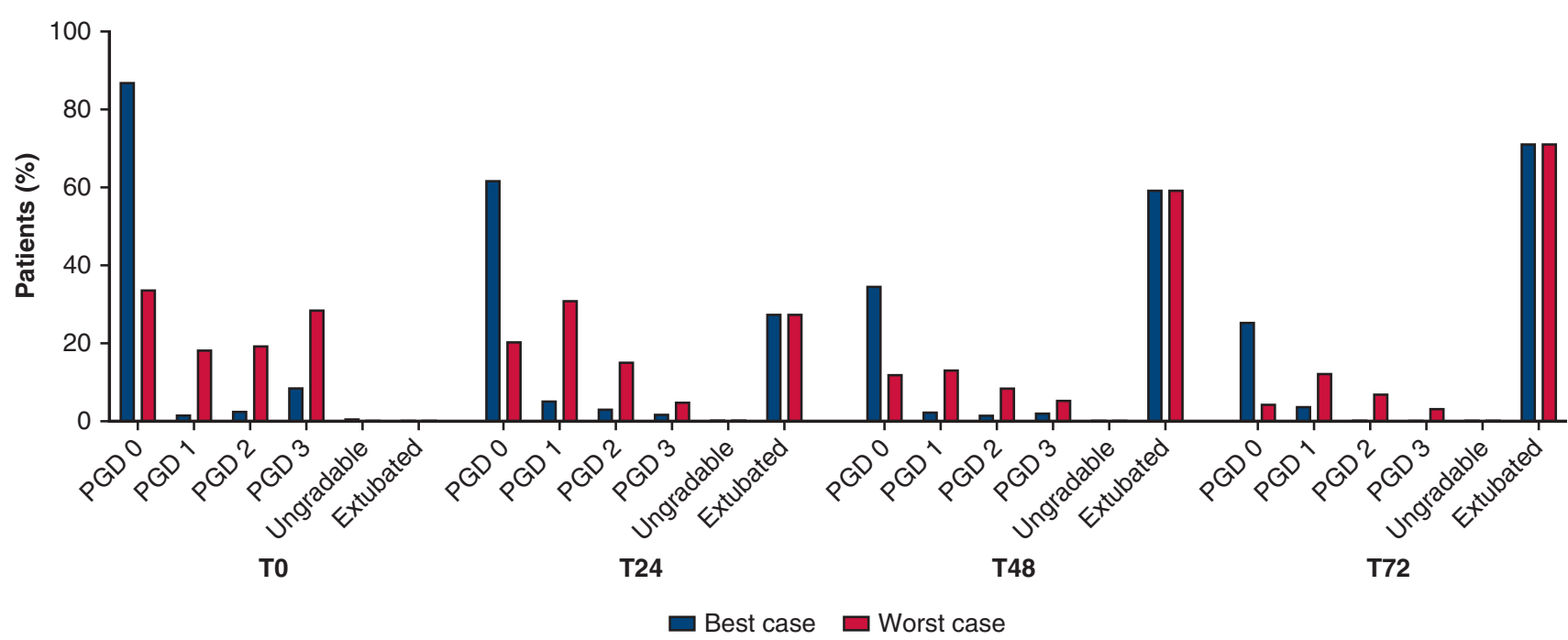

FIGURE 2. Rates of PGD were calculated for all time points according to best and worst case scenarios of the radiologic judgment. In cases of full agreement, the unanimous x-ray diagnosis was used for calculating the PGD score. For the remaining cases with a discordant x-ray reporting, PGD was graded assuming a favorable x-ray (no infiltrations) for a best case scenario and a nonfavorable x-ray (infiltrations present) for a worst case scenario. This led to a large variation in PGD rates highlighting the heavy reliance of the current PGD scoring system on the radiologic component. PGD, Primary graft dysfunction; $t 0,0$ to 6 hours; $t 24,24$ hours; $t 48,48$ hours; $t 72,72$ hours. 
TABLE 1. Summary of patient demographics for the full cohort $(n=497)$ and the random subgroup of 100 patients

\begin{tabular}{|c|c|c|}
\hline & Full cohort $(n=497)$ & Random subgroup $(n=100)$ \\
\hline Age $($ mean \pm SD) & $45.8 \pm 16.0$ & $47.0 \pm 15.0$ \\
\hline Gender $(\mathrm{m} \% / \mathrm{w} \%)$ & $51.1 / 48.9$ & $52.0 / 48.0$ \\
\hline Height $(\mathrm{cm})($ mean $\pm \mathrm{SD})$ & $167 \pm 11$ & $169 \pm 10$ \\
\hline Weight $(\mathrm{kg})($ mean $\pm \mathrm{SD})$ & $61 \pm 16$ & $62 \pm 15$ \\
\hline $\mathrm{BMI}($ mean $\pm \mathrm{SD})$ & $22 \pm 4$ & $21 \pm 4$ \\
\hline \multicolumn{3}{|l|}{ Diagnosis $(\mathrm{n} ; \%)$} \\
\hline COPD & $179(36.0)$ & $38(38.0)$ \\
\hline Fibrosis & $123(24.7)$ & $20(20.0)$ \\
\hline Cystic fibrosis & $122(24.5)$ & $22(22.0)$ \\
\hline Primary pulmonary hypertension & $8(1.6)$ & $2(2.0)$ \\
\hline $\mathrm{A} 1 \mathrm{AD}$ & $25(5.0)$ & $6(6.0)$ \\
\hline Bronchiectasis & $9(1.8)$ & $4(4.0)$ \\
\hline LAM & $9(1.8)$ & $2(2.0)$ \\
\hline Sarcoidosis & $6(1.2)$ & $3(3.0)$ \\
\hline Other & $16(3.2)$ & $3(3.0)$ \\
\hline Pulmonary hypertension (n; \%) & $35(7.0)$ & $8(8.0)$ \\
\hline Waiting time $(\mathrm{d})($ mean $\pm \mathrm{SD})$ & $168 \pm 177$ & $173 \pm 182$ \\
\hline High urgent recipients $(\mathrm{n} ; \%)$ & $47(9.5)$ & $7(7.0)$ \\
\hline Intubation before transplant (n; \%) & $28(5.6)$ & $4(4.0)$ \\
\hline Extracorporeal life support bridging $(\mathrm{n} ; \%)$ & $18(3.6)$ & $4(4.0)$ \\
\hline Donor last $\mathrm{PaO} 2$ at $\mathrm{FiO} 2=1.0($ mean $\pm \mathrm{SD})$ & $448 \pm 100$ & $438 \pm 100$ \\
\hline Donor last $\mathrm{PaCO} 2$ at $\mathrm{FiO} 2=1.0($ mean $\pm \mathrm{SD})$ & $38.8 \pm 6.4$ & $38.6 \pm 5.9$ \\
\hline Ex vivo lung perfusion (n; \%) & $53(10.7)$ & $16(16.0)$ \\
\hline Ischemic time (mean $\pm \mathrm{SD})$ & $345 \pm 72$ & $347 \pm 75$ \\
\hline \multicolumn{3}{|l|}{ Type of transplant (n; \%) } \\
\hline Whole lungs & $231(46.5)$ & $48(48.0)$ \\
\hline Size reduction & $197(39.6)$ & $40(40.0)$ \\
\hline Lobar transplant & $69(13.9)$ & $12(12.0)$ \\
\hline \multicolumn{3}{|l|}{ Type of circulatory support $(\mathrm{n} ; \%)$} \\
\hline no ECMO & $100(20.1)$ & $22(22.0)$ \\
\hline intraoperative ECMO & $372(74.8)$ & $73(73.0)$ \\
\hline postoperative prolonged ECMO & $3(0.6)$ & $1(1.0)$ \\
\hline preoperative and intraoperative ECMO & $18(3.6)$ & $3(3.0)$ \\
\hline cardiopulmonary bypass & $4(0.8)$ & $1(1.0)$ \\
\hline Surgery duration $(\mathrm{min})($ mean $\pm \mathrm{SD})$ & $281 \pm 56$ & $282 \pm 60$ \\
\hline Intraoperative transfusions (mean $\pm \mathrm{SD}$ ) & $4.0 \pm 2.7$ & $4.3 \pm 3.0$ \\
\hline FFP $($ mean \pm SD) & $10.6 \pm 4.8$ & $11.7 \pm 6.0$ \\
\hline Induction $(\mathrm{n} ; \%)$ & $382(76.9)$ & $78(78.0)$ \\
\hline
\end{tabular}

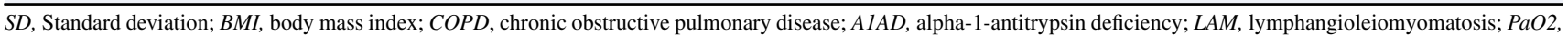
partial pressure of arterial oxygen; Fio2, fraction of inspired oxygen; PaCO2, partial pressure of arterial carbon dioxide; ECMO, extracorporeal membrane oxygenation; FFP, fresh-frozen plasma.

$\mathrm{n}=24$ at $\mathrm{t} 24, \mathrm{n}=27$ at $\mathrm{t} 48$, and $\mathrm{n}=20$ at $\mathrm{t} 72$ ). By definition, in these cases the chest radiograph diagnosis is the decisive factor between the highest and lowest PGD scores. In 134 of those 231 cases $(58.0 \%)$, no full agreement on the presence and absence of infiltrations was found among the 5 radiologists. In 92 cases $(n=72$ at $\mathrm{t} 0,6$ at $\mathrm{t} 24,9$ at $\mathrm{t} 48,5$ at t72), the majority of raters diagnosed infiltrations and the minority rated a clear chest radiograph. Therefore, a PGD grade of 3 would have been calculated according to 3 or more radiologists, but according to the other(s) a PGD 0 would have been documented. On the other hand, in 42 cases ( 23 at $\mathrm{t} 0,6$ at $\mathrm{t} 24,5$ at $\mathrm{t} 48,8$ at $\mathrm{t} 72$ ), the majoritarian 
TABLE 2. Kappa values representing interobserver agreement for the full cohort and random subgroup

\begin{tabular}{lcc}
\hline & $\begin{array}{c}\text { Full cohort }(\mathbf{n}=\mathbf{4 9 7}) \\
\text { kappa }(\mathbf{9 5} \% \mathbf{C I})\end{array}$ & $\begin{array}{c}\text { Random subgroup }(\mathbf{n}=\mathbf{1 0 0}) \\
\text { kappa }(\mathbf{9 5} \% \mathbf{C I})\end{array}$ \\
\hline $0-6 \mathrm{~h}$ & $0.456(0.43-0.48)$ & $0.335(0.27-0.40)$ \\
\hline $24 \mathrm{~h}$ & $0.456(0.43-0.48)$ & $0.322(0.26-0.38)$ \\
\hline $48 \mathrm{~h}$ & $0.405(0.38-0.43)$ & $0.365(0.30-0.43)$ \\
$72 \mathrm{~h}$ & $0.409(0.38-0.44)$ & $0.358(0.29-0.42)$ \\
\hline
\end{tabular}

CI, Confidence interval.

interpretation was "no infiltrations" but the dissenting radiologist(s) stated "infiltrations." This means that the PGD grading would have changed from 0 to 3 following the interpretation of the disagreeing rater(s).

Furthermore, we calculated PGD rates for a best case and a worst case scenario of radiologic judgment (Figure 2). The biggest difference for PGD 3 was found at t0 (best case: $8.4 \%$ vs worst case: 28.4 ). This discrepancy was less pronounced at t $24(1.8 \%$ vs $4.8 \%), \mathrm{t} 48(2.0 \%$ vs $5.3 \%)$, and t72 $(0.2 \%$ vs $3.1 \%)$. Five patients $(1.0 \%)$ were on postoperative ECMO at t0. According to current PGD criteria, 2 of them were categorized as ungradable, and 3 were graded PGD 3. Extracorporeal support was still present in 3 patients at $\mathrm{t} 24(0.6 \%), 2$ patients at $\mathrm{t} 48(0.4 \%)$, and 1 patient at $772(0.2 \%)$. According to the majority judgment of the chest radiograph, 2 patients at t 24 and 1 patient at $\mathrm{t} 48$ were found to be ungradable. One patient at $\mathrm{t} 24, \mathrm{t} 48$, and t72 was scored PGD 3. Results are summarized in Video 1.

\section{DISCUSSION}

To the best of our knowledge, this is the first large-scale study evaluating interobserver variability of chest radiographs after LTx and its impact on PGD rates. We found that radiologists blinded to the patient's clinical course had only a moderate agreement rate. This inconsistency could have led to an up- or downgrading of PGD in a significant number of patients (Graphical Abstract). In addition, we identified high BMI and size reduction as risk factors associated with discordant grading of chest radiographs. However, providing radiologists with basic preoperative and intraoperative patient characteristics did not improve chance-corrected agreement rates.
Interobserver variability of chest radiographs has been described in several smaller studies on acute respiratory distress syndrome (ARDS), which also uses a radiology-based grading system. ${ }^{7,8}$ Sjoding and colleagues ${ }^{9}$ found only a "moderate" agreement among 8 clinicians who were asked to grade 205 patients with ARDS and attributed $67 \%$ of the disagreement to the low reliability of chest radiographs. Rubenfeld and colleagues ${ }^{10}$ analyzed the results of 21 clinical care experts reviewing the x-rays of 28 patients and found only moderate agreement with a kappa of 0.55 . In addition, nearfull agreement (20/21 observers) was found in $43 \%$ of cases. In a larger study by Meade and colleagues, ${ }^{11} 2$ intensivists and 1 radiologist assessed 778 chest x-rays of 99 patients. Two raters finished a training module on ARDS chest $\mathrm{x}$-ray reporting before the study, whereas no specific training was offered to the third. In pairwise comparisons, the 2 trained raters achieved high kappa values of 0.72 to 0.88 . For all other pairings, the authors found only a level of "moderate" agreement (kappa 0.38 to 0.55 ), concluding that specific training could improve reliability. In contrast, a recent multicenter prospective study by Peng and colleagues ${ }^{12}$ found only minor improvement after specific training in 268 intensivists with a kappa of 0.133 before and 0.178 after training. Our results of interobserver variability are in line with these reports, showing only fair to moderate agreement among 5 specialist radiologists when assessing postLTx chest radiographs.

Although the radiologic criteria of ARDS are identical to those in PGD, it is important to highlight that the latter is assessing a postoperative situation. Postoperative radiographs are often difficult to interpret because of a variety of confounders, even for radiologists specialized in thoracic radiology. For example, postoperative bleeding or pleural collections could mimic bilateral infiltrations, especially in bedside chest radiographs.

Other factors frequently leading to inconsistent $\mathrm{x}$-ray interpretations are size reductions and a high recipient BMI. In patients with a high BMI, atelectasis can develop during weaning when ventilation pressures are reduced. An erroneous interpretation of atelectasis could explain impaired interobserver agreement in our study cohort at t48 and

TABLE 3. Kappa values of patients subgrouped according to body mass index and the type of transplantation/size reduction at each time point

\begin{tabular}{|c|c|c|c|c|c|c|}
\hline & $\begin{array}{c}\text { BMI }<18.5(n=125) \\
\quad \operatorname{kappa}(95 \% \text { CI })\end{array}$ & $\begin{array}{c}\text { BMI } 18.5-25(n=253) \\
\operatorname{kappa}(95 \% \text { CI })\end{array}$ & $\begin{array}{c}\text { BMI }>25(n=96) \\
\operatorname{kappa}(95 \% \mathrm{CI})\end{array}$ & $\begin{array}{l}\text { Full size }(n=231) \\
\operatorname{kappa}(95 \% \text { CI })\end{array}$ & $\begin{array}{l}\text { Size reduced }(\mathbf{n}=197) \\
\operatorname{kappa}(95 \% \mathbf{C I})\end{array}$ & $\begin{array}{r}\text { Lobar }(\mathbf{n}=69) \\
\operatorname{kappa}(95 \% \mathbf{C I})\end{array}$ \\
\hline $0-6 \mathrm{~h}$ & $0.500(0.44-0.56)$ & $0.482(0.44-0.52)$ & $0.377(0.31-0.44)$ & $0.520(0.48-0.56)$ & $0.396(0.35-0.44)$ & $0.311(0.23-0.39)$ \\
\hline $24 \mathrm{~h}$ & $0.502(0.45-0.56)$ & $0.501(0.46-0.54)$ & $0.334(0.27-0.40)$ & $0.470(0.43-0.51)$ & $0.455(0.41-0.50)$ & $0.322(0.25-0.40)$ \\
\hline $48 \mathrm{~h}$ & $0.457(0.40-0.51)$ & $0.445(0.40-0.49)$ & $0.244(0.18-0.31)$ & $0.364(0.32-0.40)$ & $0.408(0.36-0.45)$ & $0.391(0.31-0.47)$ \\
\hline $72 \mathrm{~h}$ & $0.429(0.37-0.49)$ & $0.455(0.41-0.50)$ & $0.248(0.18-0.31)$ & $0.352(0.31-0.39)$ & $0.440(0.40-0.49)$ & $0.325(0.27-0.40)$ \\
\hline
\end{tabular}

$B M I$, Body mass index; $C I$, confidence interval. 


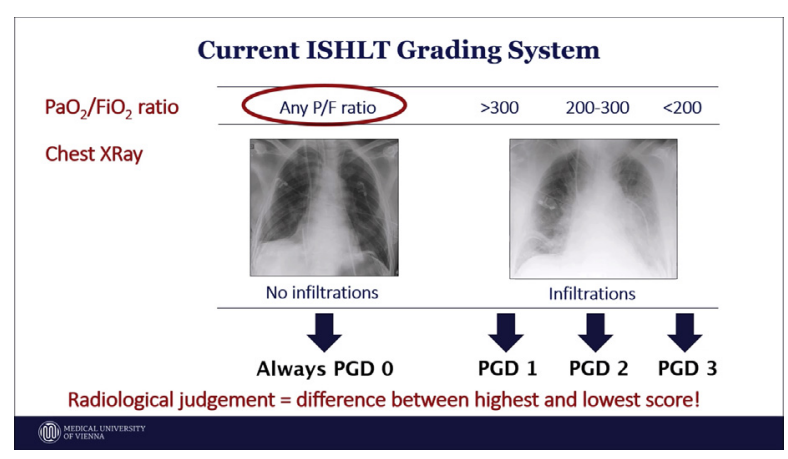

VIDEO 1. Summary of the study rationale and overview of the most important findings and results. Video available at: https://www.jtcvs.org/ article/S0022-5223(19)30974-2/fulltext.

t72. Moreover, extra-anatomic size reduction, such as removal of the middle lobe and lingula, usually results in bilateral hilar opacities. This can be easily misjudged as bilateral infiltrations, especially because the lung parenchyma next to the resection line can sometimes be congested. To the best of our knowledge, extra-anatomic size reductions are not a risk factor for the development of a reperfusion edema ${ }^{13,14}$; however, radiographs of patients with size-reduced LTx showed markedly lower chance-corrected agreement rates among the 5 observers.

In daily routine, radiologists often lack full clinical background information of patients at the time they report on chest radiographs. Therefore, in this study the 5 raters were primarily blinded to clinical patient details. Ideally, radiologists should have full access to each patient's clinical data. Therefore, in a second set of analysis, we aimed to determine whether basic knowledge on clinical parameters might improve interobserver variability. Surprisingly, information on clinical parameters failed to improve interobserver agreement rates. The reason for this remains unclear. Radiologists may ascribe different degrees of importance to the additional clinical information provided, thus leading to a higher discordance. This finding represents further evidence of the difficult and subjective nature of judging postoperative chest radiographs.

Another factor worthy of discussion is that severe reperfusion edema has become rare in the modern era of LTx. A complete white-out of the chest radiographs is hardly ever seen. Instead, radiologic edematous changes tend to be subtle and therefore may be more difficult to interpret. Several factors account for the low number of severe reperfusion edema in recent series of LTx: improved donor management, optimal graft handling, and understanding the importance of controlled reperfusion. Maximal controlled reperfusion is achieved by liberal use of intraoperative ECMO. Several studies have demonstrated the benefits of controlled reperfusion for early graft function. ${ }^{15-18}$ Additionally, with a routine application of ECMO in LTx, extremely low numbers of reperfusion edema have been reported. ${ }^{19,20}$ Because this is especially true for the later time points, the discrepancies between best and worst case scenarios in our study are less profound at $\mathrm{t} 72$. This is mainly a result of the high number of patients who are already extubated and the low frequency of impaired P/F ratios at this time point. Difficulties in reporting PGD rates are further aggravated by the controversy of prophylactic postoperative venoarterial ECMO. According to the latest ISHLT recommendation, in these patients solely the radiograph decides between ungradable and PGD 3 . $^{3}$

The question remains how to address these radiologic flaws in a future revision of the PGD scoring system. An approach of a joint radiograph judgment of multiple observers might improve the validity of chest radiograph diagnoses, but will not be feasible for most transplant centers because of limited personal resources. Computed tomography for assessment of reperfusion edema has been proposed by Belmaati and colleagues, ${ }^{21}$ but is also of limited practicability in daily routine. Although PGD rates are broadly used to report outcomes, they are rarely used for treatment decisions in the early post-transplant period. Functional measurements of the transplant lungs are generally more useful. As in other reports, ${ }^{22-24} \mathrm{P} / \mathrm{F}$ ratios alone resulted in a good correlation with long-term survival in our study cohort. However, short-term outcomes such as duration of mechanical ventilation only mildly correlated with P/F ratios at the different time points. We are currently evaluating other ventilation parameters, such as peak or mean ventilation pressure, tidal volume, or dynamic pulmonary compliance, which could be used in a future PGD score. These variables seem to correlate better with actual graft performance.

\section{Study Limitations}

This study has several limitations. First, its retrospective nature poses a potential bias, and a prospective multicenter validation cohort is needed to confirm our results. Although the single-center approach guarantees a homogenous patient cohort and a consistent quality of radiologic films, variabilities between different transplant centers are neglected. In addition, our raters were not presented with single chest radiographs for grading but rather a chronologic series of $\mathrm{x}$-rays for each patient. Although this study design is close to the clinical reality, knowledge on the temporal change of $\mathrm{x}$-rays might have influenced the grading.

\section{CONCLUSIONS}

Interobserver variability in grading chest radiographs after LTx is substantial. This might have a considerable impact on clinical practice, as well as research, using the score as an outcome parameter. Future revisions of the PGD score should take this into consideration. 


\section{Webcast}

You can watch a Webcast of this AATS meeting presentation by going to: https://aats.blob.core.windows.net/media/ 18May01/25ABC \%202.General \%20Thoracic\%20SS/S89\% 20-\%20Part\%201/S89_2_webcast_022341016.mp4.

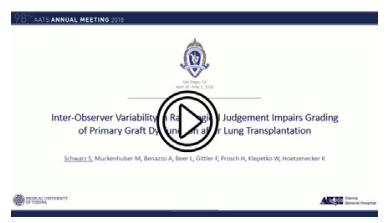

\section{Conflict of Interest Statement}

Authors have nothing to disclose with regard to commercial support.

\section{References}

1. Chambers DC, Yusen RD, Cherikh WS, Goldfarb SB, Kucheryavaya AY, Khusch K. The Registry of the International Society for Heart and Lung Transplantation: thirty-fourth adult lung and heart-lung transplantation report-2017; focus theme: allograft ischemic time. J Heart Lung Transplant. 2017;36: 1047-59.

2. Christie JD, Carby M, Bag R, Corris P, Hertz M, Weill D, et al. Report of the ISHLT Working Group on Primary Lung Graft Dysfunction part II: definition. A consensus statement of the International Society for Heart and Lung Transplantation. J Heart Lung Transplant. 2005;24:1454-9.

3. Snell GI, Yusen RD, Weill D, Strueber M, Garrity E, Reed A, et al. Report of the ISHLT Working Group on Primary Lung Graft Dysfunction, part I: definition and grading-A 2016 consensus group statement of the International Society for Heart and Lung Transplantation. J Heart Lung Transplant. 2017;36:1097-103.

4. Peck DNJ. STATS FLEISS KAPPA [computer program]. Available at: https:// www.ibm.com/developerworks/community/files/app\#/file/48234a16-fb14-4bee8c18-570319c57108. Accessed November 15, 2018.

5. Altman DG. Chapter 14: Some common problems in medical research. In: Practical Statistics for Medical Research. London: Chapman and Hall; 1991:403.

6. Landis JR, Koch GG. The measurement of observer agreement for categorical data. Biometrics. 1977;33:159-74.

7. Bernard GR, Artigas A, Brigham KL, Carlet J, Falke K, Hudson L, et al. The American-European Consensus Conference on ARDS. Definitions, mechanisms, relevant outcomes, and clinical trial coordination. Am J Respir Crit Care Med. 1994;149(3 Pt 1):818-24.

8. Ferguson ND, Fan E, Camporota L, Antonelli M, Anzueto A, Beale R, et al. The Berlin definition of ARDS: an expanded rationale, justification, and supplementary material. Intensive Care Med. 2012;38:1573-82.

9. Sjoding MW, Hofer TP, Co I, Courey A, Cooke CR, Iwashyna TJ. Interobserver reliability of the Berlin ARDS definition and strategies to improve the reliability of ARDS diagnosis. Chest. 2018;153:361-7.

10. Rubenfeld GD, Caldwell E, Granton J, Hudson LD, Matthay MA. Interobserver variability in applying a radiographic definition for ARDS. Chest. 1999;116: 1347-53.

11. Meade MO, Cook RJ, Guyatt GH, Groll R, Kachura JR, Bedard M, et al. Interobserver variation in interpreting chest radiographs for the diagnosis of acute respiratory distress syndrome. Am J Respir Crit Care Med. 2000;161:85-90.

12. Peng JM, Qian CY, Yu XY, Zhao MY, Li SS, Ma XC, et al. Does training improve diagnostic accuracy and inter-rater agreement in applying the Berlin radiographic definition of acute respiratory distress syndrome? A multicenter prospective study. Crit Care. 2017;21:12.

13. Barr ML, Kawut SM, Whelan TP, Girgis R, Bottcher H, Sonett J, et al. Report of the ISHLT Working Group on Primary Lung Graft Dysfunction part IV: recipient-related risk factors and markers. J Heart Lung Transplant. 2005;24:1468-82.

14. Whitson BA, Nath DS, Johnson AC, Walker AR, Prekker ME, Radosevich DM, et al. Risk factors for primary graft dysfunction after lung transplantation. $J$ Thorac Cardiothorac Surg. 2006;131:73-80.
15. Guth S, Prufer D, Kramm T, Mayer E. Length of pressure-controlled reperfusion is critical for reducing ischaemia-reperfusion injury in an isolated rabbit lung model. J Thorac Cardiothorac Surg. 2007;2:54.

16. Bhabra MS, Hopkinson DN, Shaw TE, Onwu N, Hooper TL. Controlled reperfusion protects lung grafts during a transient early increase in permeability Ann Thorac Surg. 1998;65:187-92.

17. Sakamoto T, Yamashita C, Okada M. Efficacy of initial controlled perfusion pressure for ischemia-reperfusion injury in a 24-hour preserved lung. Ann Thorac Cardiovasc Surg. 1999;5:21-6.

18. Hopkinson DN, Bhabra MS, Odom NJ, Bridgewater BJ, Van Doorn CA Hooper TL. Controlled pressure reperfusion of rat pulmonary grafts yields improved function after twenty-four-hours' cold storage in University of Wisconsin solution. J Heart Lung Transplant. 1996;15:283-90.

19. Hoetzenecker K, Schwarz S, Muckenhuber M, Benazzo A, Frommlet F, Schweiger $\mathrm{T}$, et al. Intraoperative extracorporeal membrane oxygenation and the possibility of postoperative prolongation improve survival in bilateral lung transplantation. J Thorac Cardiovasc Surg. 2018;155: 2193-206.e3.

20. Hoetzenecker K, Benazzo A, Stork T, Sinn K, Schwarz S, Baron D, et al. BLTX on intraoperative ECMO sets the new benchmark for postoperative graft function: results of a prospective trial. J Heart Lung Transplant 2018;37:S167-8

21. Belmaati EO, Steffensen I, Jensen C, Kofoed KF, Mortensen J, Nielsen MB, et al Radiological patterns of primary graft dysfunction after lung transplantation evaluated by 64-multi-slice computed tomography: a descriptive study. Interact Cardiovasc Thorac Surg. 2012;14:785-91.

22. Prekker ME, Nath DS, Walker AR, Johnson AC, Hertz MI, Herrington CS, et al. Validation of the proposed International Society for Heart and Lung Transplantation grading system for primary graft dysfunction after lung transplantation. $J$ Heart Lung Transplant. 2006;25:371-8.

23. Whitson BA, Prekker ME, Herrington CS, Whelan TP, Radosevich DM Hertz MI, et al. Primary graft dysfunction and long-term pulmonary function after lung transplantation. J Heart Lung Transplant. 2007;26: 1004-11.

24. Prekker ME, Herrington CS, Hertz MI, Radosevich DM, Dahlberg PS. Early trends in $\mathrm{PaO}(2)$ /fraction of inspired oxygen ratio predict outcome in lung transplant recipients with severe primary graft dysfunction. Chest. 2007;132:991-7.

Key Words: interobserver variability, lung transplantation, primary graft dysfunction

\section{Discussion}

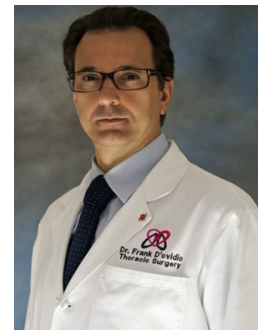

Dr Frank D'Ovidio (New York, NY). I will start by saying that grading tools are set to facilitate improved knowledge and understanding as in the case of LTx. Over time, they get refined and new classifications are generated, and your article clearly identifies one of the limitations of the current grading system for PGD.

Now, going back, whenever there is a human interpretation of a finding, it is never going to unanimous; our senses are going to be driven by our perceptions. So it would be surprising if this wasn't the case, and your article confirms this as other articles in the literature. And going along the presentation from the invited speaker today just from a methodological standpoint, did your reviewers, your radiologists, have the same monitors to review the x-rays; in other words, were their working tools standardized? 


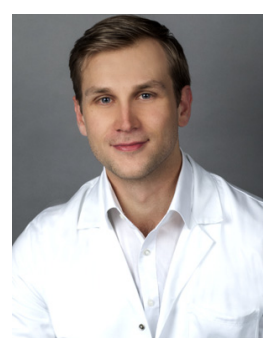

Dr Stefan Schwarz (Vienna, Austria). Yes, the working tools regarding the monitors and the viewing software were the standard equipment and software of our institution and were therefore the same for all raters.

Dr D'Ovidio. Was the subjective vision perception tested for color, in particular for the gray scale?

Dr Schwarz. No, this was not tested specifically beforehand. The raters were analyzing typical signs of pulmonary edema on chest $\mathrm{x}$-ray, such as Kerley lines, and peribronchial cuffing and patchy bilateral infiltrates, gray scale was not separately taken into account.

Dr D'Ovidio. That was more of a perception, so understanding if the readers had the same capability to interpret the gray scale. Having said that, and your answer responds a bit to the next question that I had was, were accepted criteria set up front to differentiate pulmonary edema from other type of infiltrates as you depicted from the lobar nonanatomic resections?

Dr Schwarz. The task of the radiologists was to grade these chest $\mathrm{x}$-rays according to the current PGD scoring system and its radiologic component, meaning bilateral infiltrations consistent with pulmonary edema and their respective features on chest $\mathrm{x}$-ray. These were radiologists with years of experience in the field, specialist thoracic radiologists. Because they were working in a high-volume LTx center, they were dealing with post-LTx chest x-rays on a daily basis and were proficient in this assessment. But there was no special consensus training, if you are alluding to that, beforehand.

Dr D'Ovidio. There is also literature to suggest that if there is a certain training up front before starting the study that may be helpful in augmenting the unanimous understanding or interpretation of the findings.

Dr Schwarz. That is a good point, and this is something to keep in mind for future studies. There have been studies, for example, in the field of acute respiratory distress syndrome in which raters receiving consensus training showed improved agreement rates. However, other studies did the same and didn't find this significant improvement.

Dr D'Ovidio. So are you and your group exploring other more objective tools to be implemented in the algorithm for PGD grading?

Dr Schwarz. That is an excellent point, and we are currently evaluating different parameters, for example ventilation parameters, that might be of use in future revisions of the PGD score. Peak pressure, mean pressure, tidal volume, and dynamic compliance are promising and might improve the score.

Dr D'Ovidio. Is your center using PGD as a clinical tool or a retrospective tool? In other words, are you currently prospectively evaluating the grade or is it just for reporting and interpretation of it?

Dr Schwarz. At our center, we prospectively report and document PGD at every time point for every patient and use it as a major outcome parameter for research.

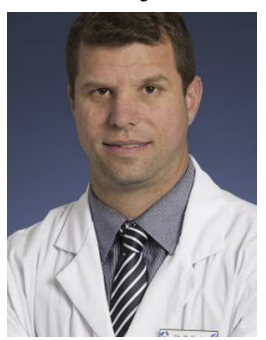

Dr Marcelo Cypel (Toronto, Ontario, Canada). That is a great study. It is too bad that this was not really analyzed before the current classification just published recently. But it has been always I think my concern of underreporting of PGD grades in the literature because of this $\mathrm{X}$-ray interpretation. Just a few years ago I reviewed an article for donation after cardiac death LTx in which half of the patients had P/F ratios less than 200 but yet the PGD 3 rates were $10 \%$, and I never could understand that. Really, a patient who arrives in the intensive care unit with a low $\mathrm{P} / \mathrm{F}$ ratio after LTx, with rare exceptions, that's a PGD, and I don't know why we are still classifying them as PGD 0 if the P/ $\mathrm{F}$ ratio was 150 and the $\mathrm{x}$-ray is interpreted as clear. Do you think we should take the x-ray completely out of the classification as a solution?

Dr Schwarz. Well, that's something that has to be discussed in the next revisions of the score. The solution would be taking it completely out or at least introducing other parameters such as ventilatory parameters, as we have mentioned, to improve the score. 
TABLE E1. Primary graft dysfunction grades according to current International Society for Heart and Lung Transplantation guidelines

\begin{tabular}{lcc}
\hline PGD grade & Chest radiograph & $\mathbf{P a O}_{2} / \mathbf{F i O}_{2}$ ratio \\
\hline Grade 0 & No infiltration & Any \\
Grade 1 & Infiltration & $>300$ \\
Grade 2 & Infiltration & $200-300$ \\
Grade 3 & Infiltration & $<200$ or ECLS \\
Ungradable & No infiltration & ECLS \\
\hline
\end{tabular}

$\overline{P G D}$, Primary graft dysfunction; $\mathrm{PaO}_{2} / \mathrm{FiO}_{2}$, partial pressure of arterial oxygen/fraction of inspired oxygen; ECLS, extracorporeal life support.

TABLE E2. Scale used for interpretation of kappa values and their corresponding level of chance-corrected agreement

\begin{tabular}{lcc}
\hline & \multicolumn{2}{c}{ Strength of agreement } \\
\cline { 2 - 3 } Kappa value & Landis and Koch & Altman \\
\hline$<0.00$ & Slight & - \\
$0.00-0.20$ & Fair & Poor \\
$0.21-0.40$ & Moderate & Fair \\
$0.41-0.60$ & Substantial & Moderate \\
$0.61-0.80$ & Almost perfect & Good \\
$0.81-1.00$ & & Very good \\
\hline
\end{tabular}

